\title{
Uji dan Karakterisasi Serbuk Pektin Hasil Ekstraksi Albedo Durian sebagai Kandidat Eksipien Farmasi
}

\author{
Patihul Husni1,*, Uvita Kafilatul Ikhrom², Uswatul Hasanah³ \\ 1Departemen Farmasetika dan Teknologi Farmasi, Fakultas Farmasi, Universitas Padjadjaran, \\ Jatinangor, Indonesia \\ 2Program Studi Farmasi, Fakultas Matematika dan Ilmu Pengetahuan Alam, Universitas Al-Ghifari, \\ Bandung, Indonesia \\ ${ }^{3}$ Fakultas Farmasi, Universitas Andalas, Kampus Limau Manis, Padang, Indonesia \\ *Email: patihul.husni@unpad.ac.id \\ (Submit 14/5/2021, Revisi 1/6/2021, Diterima 17/6/2021, Terbit 20/6/2021)
}

\section{Abstrak}

Pektin adalah senyawa polisakarida yang larut dalam air dan merupakan asam-asam pektinat yang mengandung gugus-gugus metoksil. Fungsi utamanya sebagai bahan pengental dan pembentuk gel. Bagian kulit dalam durian yang berwarna putih (mesocarp) dapat dimanfaatkan sebagai sumber pektin. Tujuan dari penelitian ini adalah untuk melakukan karakterisasi serbuk pektin albedo durian yang dihasilkan dan mengetahui kualitas serbuk eksipien pharmaceutical grade dari pektin albedo durian. Penelitian ini dilakukan dengan metode refluks menggunakan pelarut asam sulfat pada kondisi keasaman pelarut $\mathrm{pH} 2, \mathrm{pH} 3$, dan $\mathrm{pH} 4$, waktu ekstraksi 5 jam dan pada suhu $90^{\circ} \mathrm{C}$. Hasil penelitian menunjukkan bahwa karakteristik pektin $\mathrm{pH} 3$ lebih memenuhi kriteria sebagai eksipien pharmaceutical grade karena laju alir yang paling baik yaitu 4,368 $\mathrm{g} /$ detik, kerapatan mampat $0,590 \mathrm{~g} / \mathrm{mL}$, kompresibilitas $11,802 \%$, sudut istirahat $20,124^{\circ}$, susut pengeringan $10 \%$, kadar $\mathrm{Pb} 7,075$ bpj dan kadar abu $10,760 \%$.

Kata kunci: karakterisasi, albedo durian, pektin, eksipien 


\section{Pendahuluan}

Durian (Durio zibethinus L.) merupakan buah yang memiliki aroma yang sangat khas dan banyak diminati masyarakat karena memiliki rasa enak dan aroma yang harum. Buah durian terdiri dari tiga bagian, yaitu daging buah sekitar $20-35 \%$, biji sekitar $5-15 \%$ sisanya berupa bobot kulit yang mencapai $60-75 \%$ dari bobot total buah ${ }^{1}$. Durian memiliki kulit yang keras dan tebal. Apabila dilihat dari karakteristik bentuk dan sifatsifat kulitnya, banyak manfaat yang dapat dihasilkan dari kulit buahnya misalnya untuk bahan campuran papan partikel, papan semen, arang briket, arang aktif, filter, campuran untuk bahan baku obat nyamuk dan lain-lain2, 3 . Bagian kulit buah durian yang dapat dimanfaatkan sebagai sumber pektin yaitu pada bagian kulit dalam durian yang berwarna putih yang disebut juga dengan mesocarp ${ }^{4-6}$. Kandungan pektin dalam kulit buah durian sebesar $2,56 \%$.

Data statistik menunjukkan bahwa kebutuhan pektin di kawasan Asia, termasuk juga Indonesia pada tahun 2000 sampai 2009, terus mengalami peningkatan ${ }^{7}$. Untuk memenuhi kebutuhan akan pektin, maka kulit durian yang dibuang dapat dimanfaatkan untuk diolah dan diambil pektinnya.

Pektin adalah senyawa polisakarida yang larut dalam air dan merupakan asam-asam pektinat yang mengandung gugus-gugus metoksil. Fungsi utamanya sebagai bahan pengental dan pembentuk gel ${ }^{7-9}$. Selain dalam industri makanan, pektin dapat digunakan dalam industri kosmetik dan farmasi seperti pembuatan krim, sabun, minyak rambut dan pasta ${ }^{8,10}$.

Mutu pektin terlihat dari jumlah kandungan metoksilnya, jika kandungan metoksil 2,3\% sampai 4,5\% maka termasuk pektin metoksil rendah, dan bila kandungan metoksilnya lebih dari 7,12\% termasuk pektin metoksil tinggi ${ }^{7,10}$. Kandungan metoksil pada pektin ini akan menentukan mudah atau tidaknya membentuk gel dan merupakan sifat penting dari pektin ${ }^{7}$. Pektin digunakan terutama sebagai gelling agent dalam jeli, selai, dan produk lainnya. Pektin juga ditemukan dalam buah-buahan dan sayuran untuk menahan sel-sel tumbuhan. Secara struktural, pektin adalah polimer rantai panjang asam a-d-galakturonat yang merupakan asam yang berasal dari gula galaktosa sederhana. Pektin larut dalam air dan dalam kondisi yang sesuai membentuk gel ${ }^{11}$. Pemisahan pektin dari jaringan tanaman dapat dilakukan dengan cara ekstraksi. Pektin dapat larut dalam berbagai pelarut seperti air, beberapa senyawa organik, senyawa alkalis dan asam. Ekstraksi pektin menggunakan pelarut asam merupakan cara ekstraksi yang umum digunakan karena kemungkinan terjadi kerusakan pektin lebih sedikit. Hasil ekstraksi yang optimal dilakukan dengan pengaturan tingkat keasaman $(\mathrm{pH})$, suhu dan lama hidrolisis ${ }^{12}$. Standar mutu pektin berdasarkan International Pectin Producers Association (IPPA) tertera pada Tabel 1 dan spesifikasi pektin sebagai eksipien dalam Handbook of Pharmaceutical Excipients (2009) tertera pada Tabel 2. 
Tabel 1. Standar Mutu Pektin Berdasarkan International Pectin Producers Association $(\text { IPPA })^{13}$

\begin{tabular}{cc}
\hline Faktor Mutu & Kandungan \\
\hline Kekuatan gel & Minimal 150 grade \\
Kandungan metoksil: pektin bermetoksil tinggi & $>7,12 \%$ \\
Kandungan metoksil: pektin bermetoksil rendah & $2,5-7,12 \%$ \\
Kadar asam galakturonat & Minimal 35\% \\
Susut pengeringan & Maksimal 12\% \\
Kadar abu & Maksimal 10\% \\
Kadar air & Maksimal 12\% \\
Derajat esterifikasi untuk pektin ester tinggi & Minimal 50\% \\
Derajat esterifikasi untuk pektin ester rendah & Maksimal 50\% \\
Bilangan asetil & $0,15-0,45 \%$ \\
Berat ekivalen & $600-800$ mg \\
\hline
\end{tabular}

Tabel 2. Spesifikasi Pektin dalam Handbook of Pharmaceutical Excipients (2009) ${ }^{8}$

\begin{tabular}{cc}
\hline Spesifikasi & Kandungan \\
\hline Organoleptis & $\begin{array}{c}\text { Serbuk kasar atau halus, berwarna putih } \\
\text { kekuningan, hampir tidak berbau, } \\
\text { mempunyai rasa musilago. }\end{array}$ \\
Susut Pengeringan & $6,0-7,2$ \\
Kelarutan & $\leq 10 \%$ \\
& Larut dalam air, tidak larut dalam etanol \\
Identifikasi & $(95 \%)$ dan pelarut organik lain. \\
Arsenik & + \\
Timbal & $\leq 3 \mathrm{ppm}$ \\
Batas mikroba & $\leq 5 \mu \mathrm{g} / \mathrm{g}$ \\
Gula dan asam-asam organik & + \\
Kadar gugus-gugus metoksi & + \\
Kadar asam galakturonat & $\leq 6,7 \%$ \\
& $\leq 74,0 \%$ \\
\hline
\end{tabular}


Urgensi penelitian ini adalah untuk menentukan kondisi optimal ekstraksi pektin dengan pengaturan tingkat keasaman $(\mathrm{pH})$ sehingga dihasilkan serbuk pektin bersumber dari albedo durian yang memenuhi kualitas serbuk eksipien pharmaceutical grade menurut spesifikasi dalam Handbook of Pharmaceutical Excipients (2009) dalam upaya peningkatan nilai ekonomis dari kulit durian yang tidak dimanfaatkan sehingga dapat membantu memenuhi kebutuhan pektin serta mengurangi pencemaran lingkungan dari kulit durian yang tidak dimanfaatkan tersebut. Pektin yang dihasilkan ditujukan untuk digunakan sebagai eksipien pada sediaan cair seperti emulsi, sediaan setengah padat seperti gel, dan sediaan padat seperti tablet serta untuk penggunaan lainnya.

\section{Metode}

Penelitian ini menggunakan metode eksperimental di laboratorium meliputi pengumpulan bahan baku, determinasi tanaman, pembuatan serbuk simplisia dan skrining fitokimia, ekstraksi, pengendapan pektin dan pemurniannya, dan uji dan karakterisasi pektin.

\section{Pengumpulan bahan baku dan determinasi tanaman}

Spesifikasi bahan baku berupa kulit durian yang masih segar dan belum kering. Kulit durian tersebut diperoleh dari penjual buah segar dan olahan durian di Kecamatan Sumur Bandung, Kota Bandung. Determinasi tanaman dilakukan di Herbarium Jatinangor, Laboratorium Taksonomi Tumbuhan, Departemen Biologi, FMIPA UNPAD.

\section{Pembuatan serbuk simplisia dan skrining fitokimia}

Pembuatan serbuk simplisia albedo durian mengacu kepada penelitian yang sudah dipublikasikan dan dilakukan dengan modifikasi yaitu albedo durian yang telah dibersihkan dari durinya lalu dipotong tipis dan dikeringkan menggunakan oven pada suhu $45^{\circ} \mathrm{C}$ selama 12 jam dan kemudian dihaluskan menggunakan blender hingga membentuk serat kulit durian 6 . Simplisia halus siap digunakan untuk ekstraksi. Skrining fitokimia yang dilakukan meliputi uji karbohidrat berupa uji Molisch dan uji Benedict.

\section{Ekstraksi, pengendapan pektin dan pemurniannya}

Ekstraksi dilakukan dengan memanaskan 30 gram serbuk albedo durian ditambah dengan aquades dan $\mathrm{H}_{2} \mathrm{SO}_{4}$ sesuai dengan variasi keasamaan $(\mathrm{pH} 2, \mathrm{pH} 3$, dan $\mathrm{pH}$ 4) kemudian dipanaskan pada suhu $90^{\circ} \mathrm{C}$ selama 5 jam. Setelah direfluks, ekstrak disaring menggunakan kain saring dan didapat filtrat. Filtrat ditambahkan etanol 96\%. Endapan yang dihasilkan dipisahkan dari larutan. Endapan lalu dicuci menggunakan etanol $70 \%$ untuk menghilangkan sisa asam. Pektin basah yang didapatkan dikeringkan menggunakan oven pada suhu $45^{\circ} \mathrm{C}^{14}$. Rendemen pektin yang dihasilkan berupa persentase berat pektin kering yang diperoleh terhadap berat simplisia yang digunakan ${ }^{15}$. 


\section{Uji laju alir, kerapatan mampat, kompresibilitas, dan sudut istirahat serbuk pektin}

\section{Uji laju alir}

Sebanyak 20 gram serbuk pektin ditimbang. Kemudian, dituang melalui tepi corong secara perlahan-lahan ke dalam corong yang bagian bawahnya tertutup. Tutup corong bagian bawah dibuka dan pektin dibiarkan mengalir keluar. Lalu dicatat waktu yang diperlukan semua sampel untuk melewati corong dengan menggunakan stopwatch. Kecepatan alir yang baik adalah tidak kurang dari $4 \mathrm{~g} / \mathrm{detik}^{16}$.

\section{Uji kerapatan mampat}

Pemeriksaan kerapatan mampat pektin dapat dilakukan dengan cara serbuk ditimbang sebanyak 10 gram lalu dimasukan ke dalam gelas ukur $50 \mathrm{~mL}$ (pemeriksaan bobot jenis nyata), diketuk-ketuk sebanyak 300 kali untuk menentukan bobot jenis mampat sampai terdapat volume konstan ${ }^{16}$. Nilai kerapatan mampat didapatkan dengan membagi bobot sampel $(\mathrm{g})$ dengan volume serbuk setelah diketuk $(\mathrm{mL})$.

\section{Uji kompresibilitas}

Timbang 50 gram serbuk pektin dan masukkan ke dalam gelas ukur dan dicatat volumenya. Kemudian serbuk dimampatkan sebanyak 500 kali ketukan dengan alat uji. Catat volume sebelum dimampatkan (V0) dan volume setelah dimampatkan dengan pengetukan 500 kali $(\mathrm{V})$. Indeks kompresibilitas $(\mathrm{I})=(\mathrm{V} 0-\mathrm{V}) / \mathrm{V} 0 \times 100 \%$. Syarat tidak boleh lebih dari $20 \%{ }^{17}$. Nilai kompresibilitas berhubungan dengan nilai Rasio Hausner, Rasio Hausner adalah rasio antara densitas bulk material setelah dipadatkan dengan guncangan (tapped) terhadap densitasnya tanpa pemadatan.

\section{Uji sudut istirahat}

Serbuk pektin ditimbang sebanyak 25 gram dan dimasukkan ke dalam corong alir, lalu permukaan diratakan, sampel dibiarkan mengalir dan ditentukan tinggi $(\mathrm{H})$ dan jari-jari (R) dari tumpukan serbuk tersebut. Tan $\alpha=H / R$, dimana $\alpha$ adalah sudut istirahat $\left({ }^{\circ}\right)$. Tinggi dan jari-jari dalam $\mathrm{cm}^{16}$.

\section{Karakterisasi serbuk pektin}

\section{Identifikasi kualitatif}

Panaskan 1 gram zat dengan $9 \mathrm{~mL}$ air di atas tangas uap hingga terbentuk larutan, ganti air yang hilang karena penguapan. Hasil positif ditunjukan dengan terbentuk gel pada pendinginan ${ }^{18}$. Pada $5 \mathrm{~mL}$ larutan (1 dalam 100) tambahkan $1 \mathrm{~mL}$ natrium hidroksida $2 \mathrm{~N}$, biarkan pada suhu ruang selama 15 menit. Hasil positif ditunjukkan dengan terbentuk gel atau semigel ${ }^{18}$. 


\section{Organoleptis}

Uji organoleptis dilakukan dengan pengamatan langsung pada serbuk pektin, meliputi pengamatan warna, tekstur, bau dan rasa. Serbuk kasar atau halus, berwarna putih kekuningan, hampir tidak berbau, mempunyai rasa musilago ${ }^{18}$.

\section{Kelarutan}

Pektin hampir larut sempurna dalam 20 bagian air, membentuk cairan kental, opalesen, larutan koloidal mudah dituang dan bersifat asam pada kertas lakmus; praktis tidak larut dalam etanol atau pelarut organik lain. Pektin larut dalam air lebih cepat jika permukaan dibasahi dengan etanol, dengan gliserin, atau dengan sirup simpleks, atau jika permukaan dicampur dengan 3 bagian atau lebih sukrosa ${ }^{18}$.

\section{$\mathrm{pH}$}

Sebanyak 1 gram serbuk pektin didispersikan dalam $10 \mathrm{~mL}$ aquades dan ditentukan $\mathrm{pH}$-nya menggunakan $\mathrm{pH}$ meter ${ }^{16}$. Sifat khas dari pektin memiliki $\mathrm{pH}$ antara $6,0-7,2^{8}$.

\section{Susut pengeringan}

Timbang pektin sebanyak 2 gram. Timbang cawan tertutup yang telah dikeringkan selama 30 menit pada kondisi seperti yang akan digunakan dalam penetapan. Masukkan pektin ke dalam cawan dan timbang seksama cawan beserta isinya. Masukan ke dalam oven, buka tutup dan biarkan tutup di dalam oven. Panaskan pektin pada suhu dan waktu tertentu seperti tertera dalam monografi. Pada waktu oven dibuka, cawan segera ditutup dan dibiarkan sampai suhunya mencapai suhu kamar sebelum ditimbang. Susut pengeringan pektin tidak lebih dari $10,0 \%$. Pengeringan dilakukan pada suhu $105^{\circ} \mathrm{C}$ selama $3 \mathrm{jam}^{18}$. Susut pengeringan $(\%)=($ berat awal-berat akhir)/berat awal x 100\%.

\section{Kadar abu}

Cawan crusible yang akan digunakan, dikeringkan dalam tanur pada suhu $600^{\circ} \mathrm{C}$ selama 3 jam. Selanjutnya didinginkan dalam desikator dan ditimbang. Pektin ditimbang sebanyak 1 gram dalam cawan crusible kemudian dimasukkan ke dalam tanur pada suhu $600^{\circ} \mathrm{C}$ selama 6 jam kemudian didinginkan dalam desikator, perlakuan diulang hingga diperoleh bobot tetap.

\section{Cemaran logam berat timbal $(P b)$}

Sampel dihaluskan kemudian dipanaskan pada suhu $215^{\circ} \mathrm{C}$ untuk mengurangi kadar air dan minyak, kemudian diarangkan. Arang sampel diabukan pada suhu $600^{\circ} \mathrm{C}$ selama 4 jam dalam furnace. Abu yang telah dingin dari tahap preparasi kemudian ditambahkan dengan $\mathrm{HNO}_{3}$ pekat $1 \mathrm{~mL}$ dan diencerkan dengan akuades hingga total volume $10 \mathrm{~mL}$. 
Tujuan penambahan dengan $\mathrm{HNO}_{3}$ adalah untuk melarutkan logam yang telah terdekstruksi dari sampel organik dalam proses kalsinasi (pengabuan), yaitu $\mathrm{Pb}$. Campuran disaring, dan filtrat dianalisis dengan spektrofotometri serapan atom ${ }^{19}$. Menurut Kemenkes RI, 2014 cemaran logam timbal (Pb) tidak lebih dari 5 bpj ${ }^{18}$.

\section{Hasil dan Pembahasan}

Determinasi tanaman dilakukan di Herbarium Jatinangor, Laboratorium Taksonomi Tumbuhan, Departemen Biologi, FMIPA UNPAD. Berdasarkan lembar identifikasi tanaman No.072/HB/02/2019 menunjukan bahan baku yang digunakan dalam penelitian ini benar adalah tanaman durian (Durio zibethinus L.). Hasil skrining fitokimia uji karbohidrat menunjukan hasil positif dimana pada larutan sampel terbentuk lapisan cincin ungu pada uji Molisch dan terbentuk endapan merah bata pada uji Benedict. Hal ini menunjukan terdapat kandungan karbohidrat pada sampel yang menjadi sumber adanya pektin. Rendemen pektin yang diperoleh sesuai variasi $\mathrm{pH}$ yaitu $6.80 \%(\mathrm{pH} 2)$, $4.45 \%(\mathrm{pH} 3)$, dan 3,72\% (pH 4). Hasil ekstraksi dengan pelarut asam $\mathrm{pH} 2$ menghasilkan rendemen pektin yang paling tinggi. Hal ini disebabkan reaksi hidrolisis akan semakin cepat apabila konsentrasi asam semakin tinggi dan begitupun sebaliknya. Serbuk pektin yang dihasilkan sesuai variasi $\mathrm{pH}$ ekstraksi tertera pada Gambar 1.

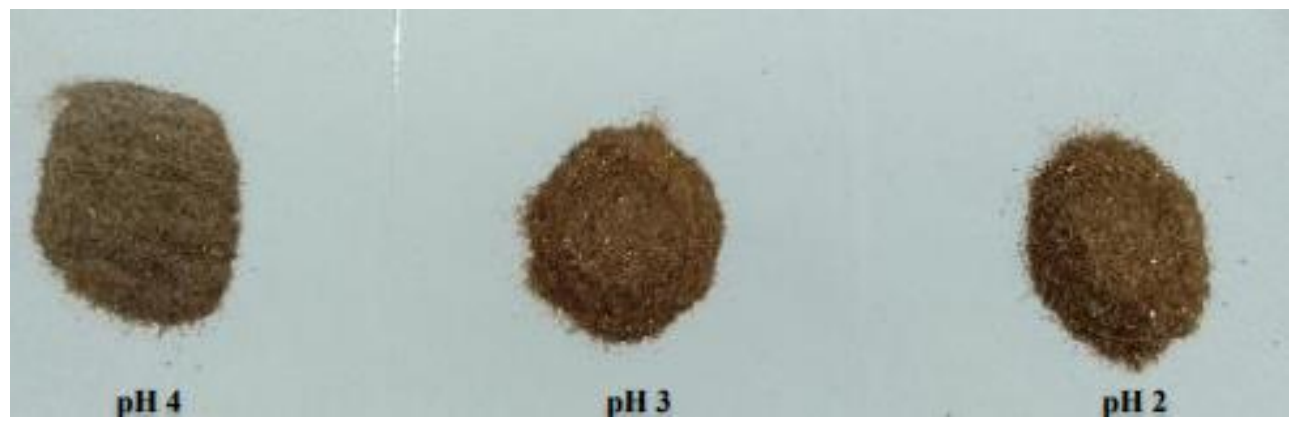

Gambar 1. Serbuk pektin sesuai variasi pH

Evaluasi sifat alir sangat penting karena berhubungan dengan keseragaman pengisian ruang cetakan yang akan mempengaruhi keseragaman bobot sediaan ${ }^{16}$. Berdasarkan hasil pada Tabel 3, laju alir semua varian $\mathrm{pH}$ serbuk pektin sesuai dengan spesifikasi literatur yaitu tidak kurang dari $4 \mathrm{~g} /$ detik. Hasil yang diperoleh memiliki kerapatan paling besar adalah $\mathrm{pH} 4$ yaitu $0,7692 \mathrm{~g} / \mathrm{mL}$. Hal ini dapat disebabkan karena ukuran partikel yang tidak homogen pada serbuk pektin sehingga partikel dapat saling mengisi didalamnya. 
Tabel 3. Hasil Uji Laju Alir, Kerapatan Mampat, Indeks Carr, Rasio Hausner dan Sudut istirahat $(n=3)$

\begin{tabular}{cccccc}
\hline $\begin{array}{c}\text { Variasi pH } \\
\text { Ekstraksi }\end{array}$ & $\begin{array}{c}\text { Laju Alir } \\
(\mathbf{g} / \text { detik })\end{array}$ & $\begin{array}{c}\text { Kerapatan } \\
\text { Mampat } \\
(\mathbf{g} / \mathbf{m L})\end{array}$ & $\begin{array}{c}\text { Indeks Carr } \\
(\%)\end{array}$ & $\begin{array}{c}\text { Rasio } \\
\text { Hausner }\end{array}$ & $\begin{array}{c}\text { Sudut } \\
\text { istirahat }\left({ }^{\circ}\right)\end{array}$ \\
\hline pH 2 & $5,695 \pm 0,19$ & $0,551 \pm 0,02$ & $17,627 \pm 2,46$ & 1,215 & $26,215 \pm 1,69$ \\
pH 3 & $4,368 \pm 0,49$ & $0,590 \pm 0,06$ & $11,802 \pm 4,28$ & 1,184 & $20,124 \pm 1,37$ \\
pH 4 & $6,817 \pm 0,49$ & $0,769 \pm 0,00$ & $27,054 \pm 1,89$ & 1,371 & $27,233 \pm 1,58$ \\
\hline
\end{tabular}

Berdasarkan Tabel 3 di atas diperoleh sampel dengan nilai \% kompresibilitas yang paling baik adalah $\mathrm{pH} 3$ yaitu $11,802 \%$. Nilai kompresibilitas yang baik berbanding lurus dengan laju alir serbuk. Semua sampel juga memiliki sudut istirahat yang digolongkan memiliki sifat alir yang sangat baik karena memiliki sudut istirahat kurang dari $30^{\circ}$. Hubungan antara laju alir serbuk, \% kompresibilitas dan rasio hausner ditunjukkan pada Tabel 4 dan hubungan sudut istirahat dan sifat alir tertera pada Tabel 5.

Tabel 4. Hubungan Laju Alir Serbuk, \% Kompresibilitas dan Rasio Hausner

\begin{tabular}{ccc}
\hline Indeks Carr (\%) & Aliran Serbuk & Rasio Hausner \\
\hline $\mathbf{1 - 1 0}$ & Sangat baik & $1,00-1,11$ \\
$\mathbf{1 1 - 1 5}$ & Baik & $1,12-1,18$ \\
$\mathbf{1 6 - 2 0}$ & Cukup & $1,19-1,25$ \\
$\mathbf{2 1 - 2 5}$ & Kurang & $1,26-1,34$ \\
$\mathbf{2 6 - 3 1}$ & Buruk & $1,35-1,45$ \\
$\mathbf{3 2 - 3 7}$ & Sangat buruk & $1,46-1,59$ \\
$>\mathbf{3 8}$ & Sangat buruk sekali & $>1,60$ \\
\hline
\end{tabular}

Tabel 5. Hubungan Sudut Istirahat dan Sifat Alir20

\begin{tabular}{cc}
\hline Sudut $\left(^{\circ}\right)$ & Sifat alir \\
\hline$\leq 30$ & Sangat baik \\
$31-35$ & Baik \\
$36-40$ & Cukup baik \\
$41-45$ & Agak baik \\
$46-55$ & Buruk \\
$\mathbf{5 6 - 6 5}$ & Sangat buruk \\
$\geq 66$ & Sangat buruk sekali \\
\hline
\end{tabular}


Identifikasi kualitatif pada sampel menunjukan hasil positif yaitu terbentuknya gel atau semigel pada larutan pektin. Hasil uji organoleptis, $\mathrm{pH}$, susut pengeringan, dan kelarutan ditunjukkan oleh Tabel 6 . Hasil uji kadar abu dan cemaran logam berat $(\mathrm{Pb})$ terdapat pada Tabel 7 . Kadar abu menyatakan banyaknya abu setelah pembakaran. Kadar abu menunjukan masih ada komponen anorganik yang tertinggal dalam pektin. Semakin kecil kadar abu maka kemurnian pektin akan semakin baik ${ }^{21}$. Kadar abu serbuk pektin adalah tidak lebih dari $10 \% 22$. Dari data yang diperoleh ketiga $\mathrm{pH}$ serbuk pektin tidak ada yang memenuhi kriteria batas maksimal 10\%. Sementara untuk cemaran logam berat $(\mathrm{Pb})$, menurut Kemenkes RI, 2014 cemaran logam timbal $(\mathrm{Pb})$ tidak lebih dari $5 \mathrm{bpj}$. Dari hasil pengujian yang memenuhi batasan nilai cemaran logam $\mathrm{Pb}$ adalah $\mathrm{pH} 4$ sebesar 3,325 bpj.

Tabel 6. Hasil Karakterisasi Sampel Serbuk Pektin Berdasarkan Kriteria Handbook of Pharmaceutical Excipients (2009)

\begin{tabular}{|c|c|c|c|c|}
\hline \multirow[b]{2}{*}{$\begin{array}{c}\text { Kriteria } \\
\text { Evaluasi }\end{array}$} & \multirow{2}{*}{$\begin{array}{c}\text { Handbook of } \\
\text { Pharmaceutical } \\
\text { Excipients, } \\
2009 \\
\end{array}$} & \multicolumn{3}{|c|}{ Sampel } \\
\hline & & $\mathrm{pH} 2$ & $\mathrm{pH} 3$ & $\mathrm{pH} 4$ \\
\hline Organoleptis & $\begin{array}{c}\text { Serbuk kasar } \\
\text { atau halus, } \\
\text { berwarna putih } \\
\text { kekuningan, } \\
\text { hampir tidak } \\
\text { berbau, } \\
\text { mempunyai rasa } \\
\text { musilago. }\end{array}$ & $\begin{array}{c}\text { Serbuk halus } \\
\text { berbentuk pipih, } \\
\text { berwarna } \\
\text { cokelat tua, } \\
\text { berbau seperti } \\
\text { agar. }\end{array}$ & $\begin{array}{c}\text { Serbuk halus } \\
\text { berbentuk pipih, } \\
\text { berwarna } \\
\text { cokelat tua } \\
\text { (lebih muda } \\
\text { dari pH 2), } \\
\text { berbau seperti } \\
\text { agar. }\end{array}$ & $\begin{array}{c}\text { Serbuk halus } \\
\text { berbentuk pipih, } \\
\text { berwarna } \\
\text { cokelat muda } \\
\text { atau } \\
\text { kecokelatan, } \\
\text { berbau seperti } \\
\text { agar. }\end{array}$ \\
\hline $\mathrm{pH}$ & $6,0-7,2$ & 4,7 & 4,8 & 5,7 \\
\hline $\begin{array}{c}\text { Susut } \\
\text { Pengeringan }\end{array}$ & $\leq 10 \%$ & $11 \%$ & $10 \%$ & $10,50 \%$ \\
\hline Kelarutan & $\begin{array}{l}\text { Larut dalam air, } \\
\text { tidak larut dalam } \\
\text { etanol (95\%) dan } \\
\text { pelarut organik } \\
\text { lain. }\end{array}$ & $\begin{array}{l}\text { Larut dalam air, } \\
\text { tidak larut } \\
\text { dalam etanol } \\
(95 \%) \text { dan } \\
\text { pelarut organik } \\
\text { lain. }\end{array}$ & $\begin{array}{l}\text { Larut dalam air, } \\
\text { tidak larut } \\
\text { dalam etanol } \\
(95 \%) \text { dan } \\
\text { pelarut organik } \\
\text { lain. }\end{array}$ & $\begin{array}{l}\text { Larut dalam air, } \\
\text { tidak larut } \\
\text { dalam etanol } \\
(95 \%) \text { dan } \\
\text { pelarut organik } \\
\text { lain. }\end{array}$ \\
\hline
\end{tabular}

Tabel 7. Hasil Uji Kadar Abu dan Cemaran Logam Berat (Pb) $(n=3)$

\begin{tabular}{ccc}
\hline $\begin{array}{c}\text { Variasi pH } \\
\text { Ekstraksi }\end{array}$ & $\begin{array}{c}\text { Kadar } \\
\text { Abu (\%) }\end{array}$ & $\begin{array}{c}\text { Cemaran Logam Berat (Pb) } \\
\text { (bpj) }\end{array}$ \\
\hline pH 2 & 11,965 & 37,525 \\
pH 3 & 10,760 & 7,075 \\
pH 4 & 11,255 & 3,325 \\
\hline
\end{tabular}


Penelitian ini merupakan tahap awal untuk pengujian dan karakterisasi serbuk pektin bersumber dari albedo kulit durian yang diperoleh dengan metode ekstraksi sebagai kandidat eksipien farmasi dimana kriteria evaluasi sampel serbuk pektin mengacu pada spesifikasi yang terdapat dalam Handbook of Pharmaceutical Excipients (2009). Standar mutu pektin berdasarkan International Pectin Producers Association (IPPA) diharapkan akan dilakukan pada penelitian selanjutnya.

\section{Kesimpulan}

Pada penelitian ini diperoleh hasil yang menunjukkan kualitas serbuk eksipien pharmaceutical grade menurut spesifikasi dalam Handbook of Pharmaceutical Excipients (2009) dari pektin albedo durian yang memenuhi kriteria adalah pada variasi $\mathrm{pH}$ ekstraksi $\mathrm{pH} 3$ dengan hasil evaluasi dan karakterisasi berupa laju alir yang paling baik yaitu $4,368 \mathrm{~g} /$ detik, kerapatan mampat $0,590 \mathrm{~g} / \mathrm{mL}$, kompresibilitas $11,802 \%$, sudut istirahat $20,124^{\circ}$, susut pengeringan $10 \%$, kadar $\mathrm{Pb} 7,075$ bpj dan kadar abu $10,760 \%$.

\section{Daftar Pustaka}

1. Untung O. Durian Untuk Kebun Komersial dan Hobi. Jakarta: Penebar Swadaya; 2008.

2. Hatta V. Manfaat kulit durian selezat buahnya. Jurnal UNLAM. 2007.

3. Rosmawati T. Pemanfaatan Limbah Kulit Durian Sebagai Bahan Baku Briket dan Pestisida Nabati. BIOSEL (Biology Science and Education): Jurnal Penelitian Science dan Pendidikan. 2016;5(2):159-70.

4. Lesmana I, Ali A, Johan VS. Variasi Konsentrasi Pektin Kulit Durian Terhadap Karakteristik Fisik Dan Mekanik Edible Film Dari Pati Ubi Jalar Ungu: Riau University; 2017.

5. Wong W, Abbas F, Liong M, Azhar M. Modification of durian rind pectin for improved biosorbent ability. International Food Research Journal. 2008;15(3):363-5.

6. Ardiansyah G, Hamzah F, Efendi R. Variasi Tingkat Keasaman Dalam Ekstraksi Pektin Kulit Buah Durian: Riau University; 2014.

7. Susilowat S. Ekstraksi Pektin dari Kulit Buah Coklat dengan Pelarut Asam Sitrat. Eksergi. 2013;11(1):27-30.

8. Rowe RC, Sheskey PJ, Quinn ME. Handbook of Pharmaceutical Expients (Sixth ed.). USA: Pharmaceutical Press.; 2009.

9. Injilauddin AS, Lutfi M, Nugroho WA. Pengaruh suhu dan waktu pada proses ekstraksi pektin dari kulit buah nangka (Artocarpus heterophyllus). Jurnal Keteknikan Pertanian Tropis dan Biosistem. 2015;3(3):280-6.

10. Sulihono A, Tarihoran B, Agustina TE. Pengaruh waktu, temperatur, dan jenis pelarut terhadap ekstraksi pektin dari kulit jeruk bali (Citrus maxima). Jurnal Teknik Kimia. 2012;18(4).

11. Vickie AV, Elizabeth WC. Essentials of Food Science: Spinger; 2014.

12. Ristianingsih Y, Nata IF, Anshori DS, Putra IPA. Pengaruh Konsentrasi $\mathrm{HCl}$ dan $\mathrm{pH}$ Pada Ekstraksi Pektin dari Albedo Durian dan Aplikasinya Pada Proses Pengentalan Karet. Konversi. 2014;3(1):32-6. 
13. Damanik DA, Pandia S. Ekstraksi Pektin dari Limbah Kulit Jeruk (Citrus sinensis) dengan Metode Ekstraksi Gelombang Ultrasonik Menggunakan Pelarut Asam Klorida (HCl). Jurnal Teknik Kimia USU. 2019;8(2):85-9.

14. Susanti D, Firdaus KDLL, Hanifa AA, Caraka FHP, Hartati I. Pelarut Terbaik Dalam Pembuatan Pektin dari Limbah Albedo Durian (Durio Zibethinus Murray) dengan Menggunakan Metode Mae (Microwave Assisted Extraction). Prosiding SNST Fakultas Teknik. 2015;1(1).

15. Rompas VF, Mamuaja CF, Suryanto E. Ekstraksi Pektin dari Lemon Cui (Citrus Microcarpa Bunge) dan Aplikasinya Pada Pembuatan Selai Nenas. J IImu dan Teknol pangan. 2016;4(2):29-36.

16. Khairunnisa R, Nisa M, Riski R, Fatmawaty A. Evaluasi Sifat Alir dari Pati Talas Safira (Colocasia esculenta var Antiquorum) Sebagai Eksipien Dalam Formulasi Tablet. Journal of pharmaceutical Medicinal Sciences. 2016;1(1):22-6.

17. Nugrahani I, Rahmat H, Djajadisastra J. Karakterisik Granul dan Tablet Propranolol Hidroklorida dengan Metode Granulasi Peleburan. Majalah IImu Kefarmasian. 2005;2(2):5.

18. Kemenkes. Farmakope Indonesia edisi V. Jakarta: Kementrian Kesehatan RI; 2014.

19. Hidayati EN. Perbandingan Metode Destruksi Pada Analisis Pb Dalam Rambut dengan AAS: Universitas Negeri Semarang; 2013.

20. Widia I, Abdassah M, Chaerunisaa AY, Rusdiana T. Karakterisasi Serbuk Selulosa Mikrokristal Asal Tanaman Rami (Boehmeria Nivea L. Gaud). Farmaka. 2017;15(3):37-46.

21. Prasetyowati P, Sari KP, Pesantri H. Ekstraksi Pektin dari Kulit Mangga. Jurnal Teknik Kimia. 2009;16(4).

22. Aziz T, Johan MEG, Sri D. Pengaruh Jenis Pelarut, Temperatur dan Waktu Terhadap Karakterisasi Pektin Hasil Ekstraksi dari Kulit Buah Naga (Hylocereuspolyrhizus). Jurnal Teknik Kimia. 2018;24(1):17-27. 